\title{
Confined Expansion and Bond Property of Micro-Expansive Concrete- Filled Steel Tube Columns
}

\author{
Xu Kai-Cheng ${ }^{1,2}$, Chen Meng-Cheng ${ }^{2, *}$ and Yuan Fang ${ }^{2}$ \\ ${ }^{1}$ School of Architecture and Civil Engineering, Nanchang University, Nanchang 330031, China \\ ${ }^{2}$ School of Civil Engineering and Architecture, East China Jiaotong University, Nanchang 330013, China
}

\begin{abstract}
The shrinkage/expansion behavior and bond carrying capacities were investigated through 4 micro-expensive concrete-filled steel tube(MCFST) and 3 conventional concrete-filled steel tube(CFST) short columns. The results show that the temperature field in MCFST is similar to that of ordinary concrete members. Concrete core has obvious effect on shrinkage-compensating with the addition of swelling agent. Pre-stress is produced in the core concrete when it is confined by the steel tube. Both water cement ratio and expansive agent have obvious influence on expansive behaviors of MCFST. The tests also indicate that the pre-stress in core concrete can improve bond strength of core concrete and steel tube of MCFST columns and proposed a new method to improve the interface bond strength of composite structures.
\end{abstract}

Keywords: Hydration heat, shrinkage/expansion behavior, bond strength, micro-expansive.

\section{INTRODUCTION}

In the past few decades, CFST have been extensively used in modern structures[1]. This is because they have high strength, high ductility, construction and convenient features. The structural benefits require stress transfer between the steel and the concrete in order to ensure their composite action. In practice, this has been attained by relying on either shear connectors on the inside of the tubes or the natural bond between steel and concrete. This bond stress transfer is not well understood.

At present, the research work mainly concentrated in the interface bond in the common steel tubeCFST [2-7]. Most of the research was focused on the bond strength of the specimen, and it indicated that there are many factors that would influence the bond capacity, such as the concrete compressing strength, the roughness of the concrete-steel interface, the ratio of the $d / t$ and the interface length, etc.

Yet initial defects will be produced in the process of construction. When the structure is enduring load, the defects will develop rapidly. Charles [8] pointed out that the shrinkage of the core concrete has obvious influence on bond strength, the shrinkage will not only lead to structural defects, but will also affect the durability of concrete. For ordinary CFST, the core concrete shrinkage will lead to deterioration or separation between the two materials. Adding expansion agent in the core concrete to form the micro-expansion concrete can effectively overcome this shortcoming, micro-expansive concrete can not only compensate for concrete shrinkage, but can also produce precompress in concrete core. It can improve the compactness

*Address correspondence to this author at the School of Civil Engineering and Architecture, East China Jiaotong University, Nanchang 330013, China; Tel: +86-791-7046085; Fax: +86-791-7046027; E-mail: xkcxj@163.Com of the core concrete and offsets the initial defects effectively [9]. This will help to improve the interface bond between steel and core concrete.

This paper focuses on the properties of hydration heat and confined expansion, which looks forward to providing dependencies for optimal design of MCFST. By adding the expansive agent to form micro-expansive concrete to improve the bond strength. In this work, first test on the steel limited expansion of micro-expansive concrete, and then on the 3 CFST and 4 MCFST push-out tests were introduced.

\section{EXPERIMENTAL ARRANGENMENTS}

To make the contrasts of confined expansion performance, 5 specimens with different expansive agents were produced, one of which adopted conventional concrete and the others with expansive concrete. The proportions of concrete are shown in Table 1. In alphabetical order P-0, P-8, P-12, P15 and $\mathrm{P}-20$, the expansive agent ratio (replace cement equivalently) is increasing. The coarse aggregate was gravel with a maximum size of $30 \mathrm{~mm}$. The expansive agent was UEA and the high-efficient water-reducing agent was PCA-IV.

In this test, the steel has the same material parameters, all square steel tube has the same cross-section length of 180 $\mathrm{mm}$ and the same length of $600 \mathrm{~mm}$, the condition of the specimens is shown in Fig. (1).

In order to observe the expansive behavior during hardening process, there are two strain gauges on each side of the specimens. As shown in Fig. (2), they can measure the longitudinal and horizontal strains at four symmetrical locations at the column middle height. Meanwhile, JMZX-215 strain gauges were embedded in the center of the specimen, which can measure transversal strain and internal temperature of the concrete core. All specimens were in the same conditi- 
Table 1. Concrete Mix Proportions(Hydration Heat Specimens)

\begin{tabular}{|c|c|c|c|c|c|c|}
\hline $\begin{array}{c}\text { Mix } \\
\text { Identification }\end{array}$ & $\begin{array}{l}\text { Water } \\
\text { (kg) }\end{array}$ & $\begin{array}{c}\text { Cement } \\
\text { (kg) }\end{array}$ & $\begin{array}{l}\text { Expansive } \\
\text { Agent (kg) }\end{array}$ & $\begin{array}{c}\text { Sand } \\
(\mathrm{kg})\end{array}$ & $\begin{array}{c}\text { Gravel } \\
\text { (kg) }\end{array}$ & $\begin{array}{c}\text { Water } \\
\text { Reducer(kg) }\end{array}$ \\
\hline P-0 & 190 & 475 & 0 & 520.5 & 1214.5 & 1.425 \\
\hline P-8 & 190 & 437 & 38 & 520.5 & 1214.5 & 1.425 \\
\hline P-12 & 190 & 418 & 57 & 520.5 & 1214.5 & 1.425 \\
\hline P-15 & 190 & 403.75 & 71.25 & 520.5 & 1214.5 & 1.425 \\
\hline P-20 & 190 & 380 & 95 & 520.5 & 1214.5 & 1.425 \\
\hline
\end{tabular}

ons, The strains and temperature are measured from $12 \mathrm{~h}$ age. Data are collected three or four times each day in the first seven days, with once a day in the following twenty-six days.

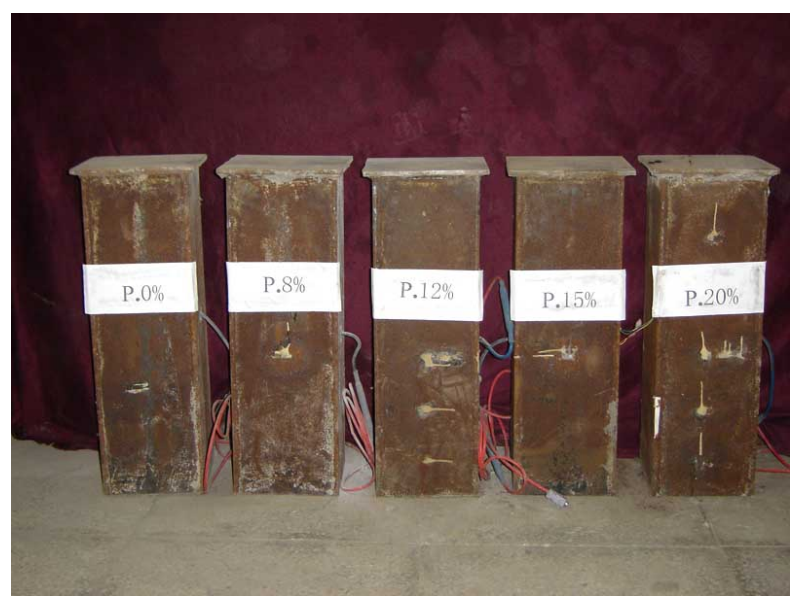

Fig. (1). 5 specimens.

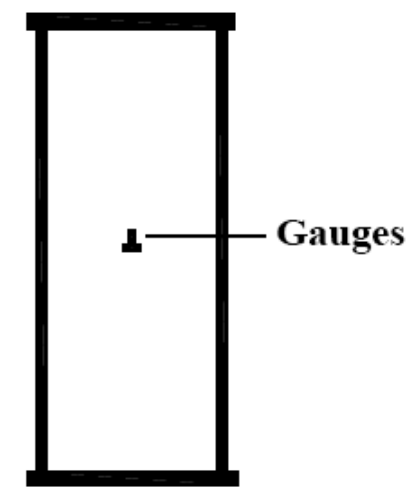

Fig. (2). Strain gauges arrangements.

To make the contrasts of bond carrying capacities and load-slip relationships of CFST specimens with those of MCFST ones, 7 kinds of concrete mixes are designed. The proportions of concrete are shown in Table 2 . The mixes ' $a$ ', ' $b$ ' and ' $c$ ' are poured with common concrete and their water-cement ratios are $0.35,0.4$ and 0.45 , respectively. The mixes ' $b$ ', ' $d$ ' and ' $f$ ' have the same water-cement ratio but expansive agent ratio is increasing. In alphabetical order 'e',
' $f$ ' and ' $g$ ', the expansive agent accounts for $12 \%$ of the cement materials based on the mixes ' $a$ ', ' $b$ ' and 'c'.

When pouring the specimens, the steel tube was erected on the flat steel plate, and then pouring the concrete through the funnel, the concrete is cast to about $20 \mathrm{~mm}$ below the top end of the specimen. In this paper, the steel has the same material parameters, all square steel tube has the same crosssection length of $160 \mathrm{~mm}$ and the same length of $600 \mathrm{~mm}$.

Push-out test arrangements are shown in Fig. (3). The use of computer controlled electro-hydraulic testing machine feeding stage loading. In the early phase, each stage loads of about $1 / 10$ of the ultimate loads, the loading speed about $500 \mathrm{~N} / \mathrm{s}$, and maintains 3 minutes. When the nonlinear sliding between the steel tube and concrete core has taken place, loading speed becomes $200 \mathrm{~N} / \mathrm{s}$. Two transducers are symmetrically attached to the steel tube to measure the slip between the concrete and steel tube. Load value directly read outs in test machine, from which we can draw the P-S curve. The parameters of the specimens are shown in Table 3 .

\section{HYDRATION HEAT OF CONCRETE CORE}

Fig. (4) shows the time-dependent temperature during hydration stage for each specimen. It is clear that the hydration heat rises rapidly in the beginning period and the peak comes after a day's pouring. The top temperature of the concrete core is about $6.5^{\circ} \mathrm{C}$ higher than that of the room . With the heat dissipating, the temperature of the concrete core is close to the surrounding temperature 2 days later. Fig. (3) indicates that the peak of the curve drops with the increase of expansive agent. This may be due to the fact that the amount of cement declines as that of expansive agent increases, which weakens hydration process on a certain degree. The hydration heat of the MCFST rises rapidly in the beginning and then drops to near the room temperature, which is similar to that of ordinary concrete members [10].

\section{EXPANSIVE/SHRINKAGE BEHAVIOR}

Figs. (5 and 6) show the expansive behaviors of the concrete and steel tube respectively for specimens ' $b$ ', ' $d$ ' and ' $\mathrm{f}$ '. It can be seen that the shrinkage of the concrete core for the CFST specimen occurs from 4 days while concrete core of the MCFST is kept in compression when in the curing stage. This can be seen that the micro-expansive concrete can not only compensate for the conventional shrinkage but also produces the pre-stress in the core concrete. The trans- 
Table 2. Concrete Mix Proportions(Push-out Test Specimens)

\begin{tabular}{|l|l|l|l|l|l|l|}
\hline $\begin{array}{l}\text { Mix } \\
\text { Identification }\end{array}$ & $\begin{array}{l}\text { Water } \\
(\mathbf{k g})\end{array}$ & $\begin{array}{l}\text { Cement } \\
\mathbf{( k g})\end{array}$ & $\begin{array}{l}\text { Expansive } \\
\text { Agent (kg) }\end{array}$ & $\begin{array}{l}\text { Sand } \\
(\mathbf{k g})\end{array}$ & $\begin{array}{l}\text { Gravel } \\
(\mathbf{k g})\end{array}$ \\
\hline \hline $\mathrm{a}$ & 160 & 457.2 & 0 & 619 & 1149.6 & 1.425 \\
\hline $\mathrm{b}$ & 190 & 475 & 0 & 520.5 & 1214.5 & 0 \\
\hline $\mathrm{c}$ & 190 & 422.5 & 0 & 572 & 1215.5 & 0 \\
\hline $\mathrm{d}$ & 190 & 437 & 38 & 520.5 & 1214.5 & 0 \\
\hline $\mathrm{e}$ & 160 & 402.2 & 55 & 619 & 1149.6 & 1214.5 \\
\hline $\mathrm{f}$ & 190 & 418 & 57 & 520.5 & 1.425 \\
\hline $\mathrm{g}$ & 190 & 371.8 & 50.7 & 572 & 1215.5 & 0 \\
\hline
\end{tabular}

versal strains increased obviously before 8-day age and almost remain same after 15-day age.

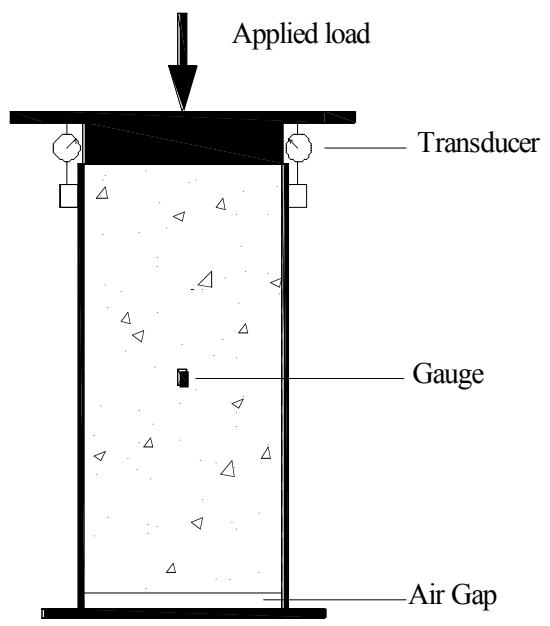

Fig. (3). Push-out test arrangement.

Fig. (6) also shows that in the same geometrical dimensions of the steel tube, the micro-expansive behavior is mainly dependent on the expansive agent ratio. The constrained expansion increases with the quantity of expansive agent.

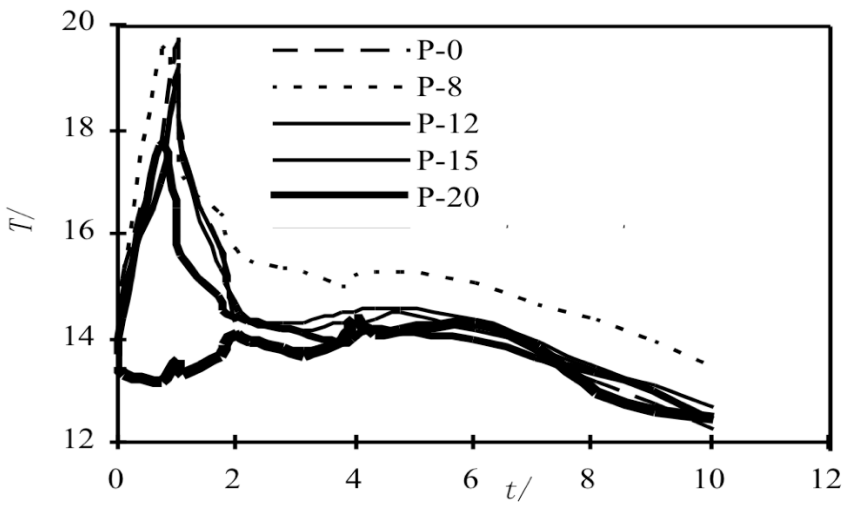

Fig. (4). Measured temperature versus time relationship.

The expansive behaviors of the steel tube for specimens 'e', ' $f$ ' and ' $g$ ' are shown in Fig. (7). It is clear that the water-cement ratio has obvious influence on the confined expansion of the MCFST columns. The constrained expansion reduces with the increase of water-cement ratio. This is because more energy will be consumed in filling pores due to the existence of pre-stress. Meanwhile, the compressive

Table 3. Summary of Test Specimens and Results

\begin{tabular}{|c|c|c|c|c|c|c|}
\hline Specimen & $D(\mathrm{~mm})$ & $L(\mathrm{~mm})$ & $T(\mathbf{m m})$ & $F_{N}(\mathbf{k N})$ & $\tau_{u}($ Мpa $)$ & $S(\mathbf{m m})$ \\
\hline $\mathrm{a}$ & 160 & 600 & 4 & 142.5 & 0.41 & 1.348 \\
\hline $\mathrm{b}$ & 160 & 600 & 4 & 132 & 0.38 & 0.917 \\
\hline $\mathrm{c}$ & 160 & 600 & 4 & 126.4 & 0.36 & 0.345 \\
\hline d & 160 & 600 & 4 & 171.3 & 0.49 & 1.474 \\
\hline $\mathrm{e}$ & 160 & 600 & 4 & 193.5 & 0.55 & 1.433 \\
\hline $\mathrm{f}$ & 160 & 600 & 4 & 182 & 0.52 & 1.615 \\
\hline $\mathrm{g}$ & 160 & 600 & 4 & 174.1 & 0.49 & 0.427 \\
\hline
\end{tabular}


strength reduces with the increase of water-cement ratio, which leads to the increase of elastic deformation and creep deformation, therefore the restriction expansion rate reduces [11].

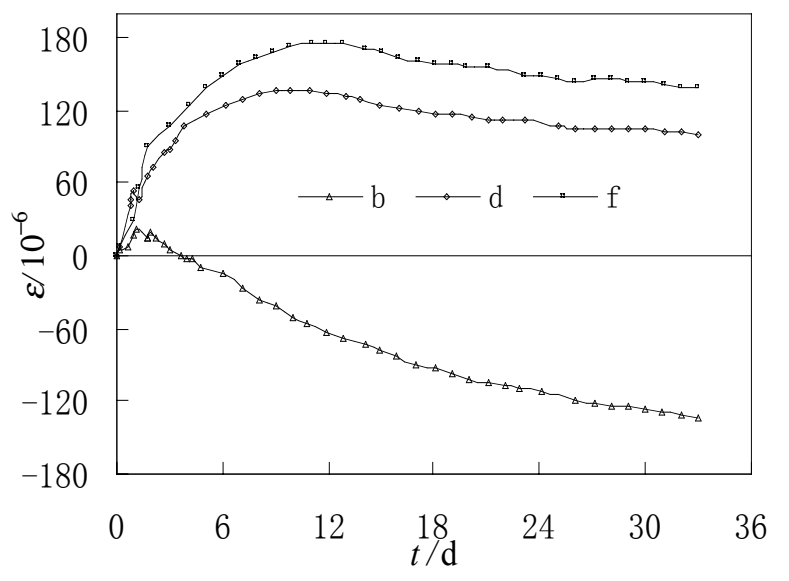

Fig. (5). Time-dependent transversal strain plot of concrete core for specimens $b, d$ and $f$.

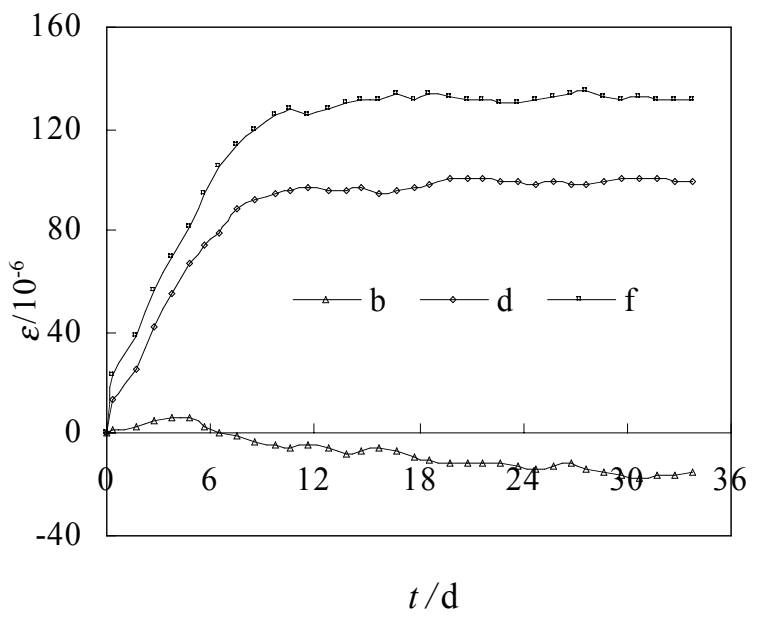

Fig. (6). Time-dependent transversal strain plot of steel tube for specimens $b, d$ and $f$.

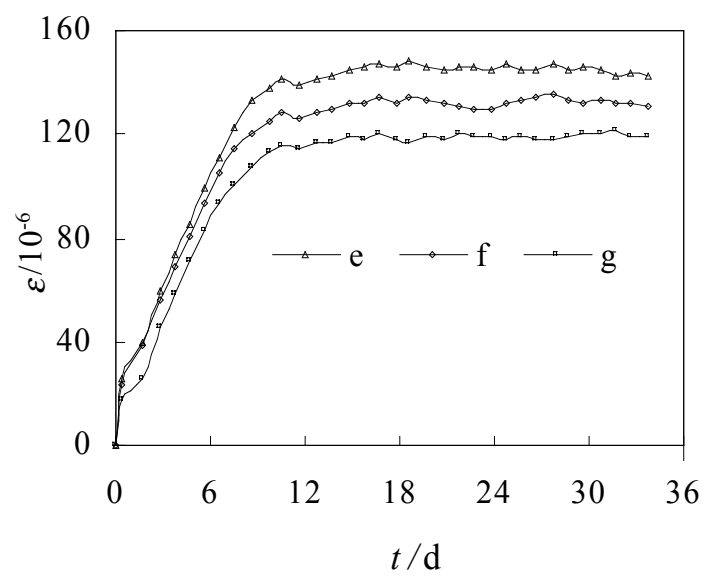

Fig. (7). Time-dependent transversal strain plot of steel tube for specimens e, f and g.

\section{PUSH-OUT TESTS OF SPECIMEN}

The bond strength is defined in the following equation:

$\tau_{\mathrm{u}}=F_{N} / 4 D L$

where $F_{N}$ is the applied load at which the bond failure occurred. $D$ and $L$ are the square steel tube cross-section length and the concrete-steel interface length, respectively. The test results are summarized in Table $\mathbf{3}$.

At the beginning of loading period, little sound can be heard and no displacement occurs. The slip increases with the increasing of the applied load, both in linear growth. For most of the specimens, a sudden brittle sound can be heard when bond failure reaches and then rigid body motion between the concrete and the steel begins with increasing slip displacements. The typical bond failure of specimen is shown in Fig. (8).

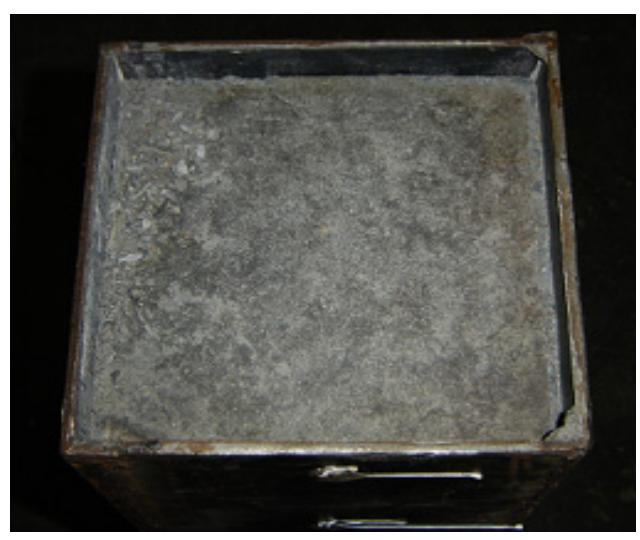

Fig. (8). The typical bond failure of the push-out test.

The load-slip relationships of specimens ' $b$ ', ' $d$ ' and ' $f$ ' are shown in Fig. (9), it can be seen that the bond carrying capacity of the CFST is lower than that of MCFST. The failure loads for specimens ' $b$ ', ' $d$ ' and 'f' are 132, 171.3 and $182 \mathrm{KN}$, the bond strengths are $0.38,0.49$ and $0.52 \mathrm{Mpa}$, respectively. It indicates that expansive/shrinkage behaviors of the concrete are important factors of the bond strength.

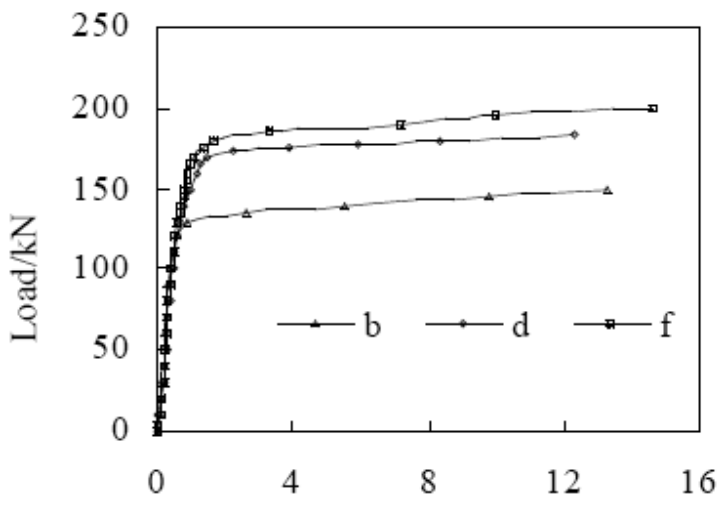

Slip displacement $/ \mathrm{mm}$

Fig. (9). Load-slip displacement curve for specimens b, $d$ and $f$. 
The different expansive agent ratio in the concrete can produce different pre-stresses in the concrete .The characteristics of the load-slip curves between the CFST and MCFST have obvious difference. In the curves' linear part, MCFST specimens have longer slip displacement and slip at a higher rate before failure load than do CFST specimens.

The load-slip relationships of specimens 'e', ' $\mathrm{f}$ ' and ' $\mathrm{g}$ ' are shown in Fig. (10). For these specimens, any parameters of specimens are the same except the water-cement ratio. The failure loads for specimens 'e', 'f' and ' $\mathrm{g}$ ' are 193, 182 and $171.3 \mathrm{KN}$, the bond strengths are $0.55,0.52$ and 0.49 $\mathrm{Mpa}$, respectively. Obviously, bond strength reduces with the increasing water-cement ratio of the concrete. This is due to the fact that bigger water-cement ratio results in smaller constrained expansion in the concrete, which induces lower bond strength.

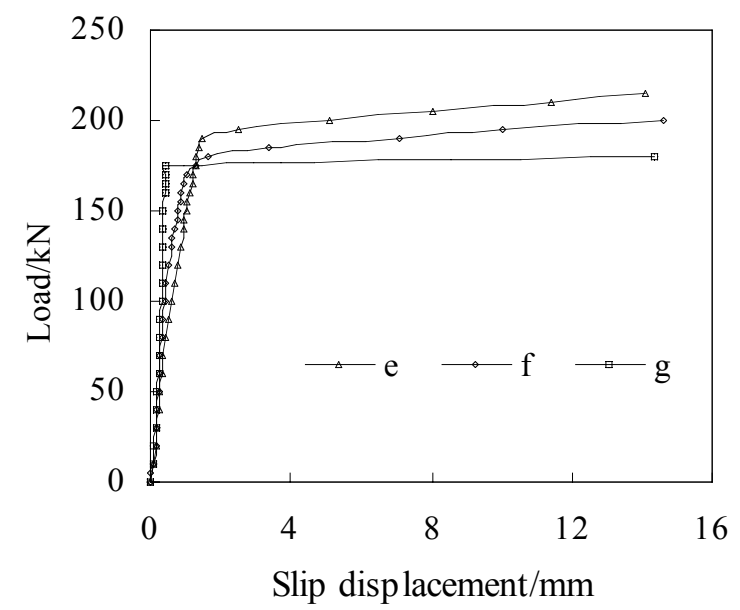

Fig. (10). Load-slip displacement curve for specimens e, f and g.

The load-strain relationships for specimen ' $e$ ' are shown in Fig. (11), which is typical for all the specimens. The steel tube strain increases from the top to the base at certain load level. This is due to the interface bond through which the load transfers from the concrete to the steel tube, as ShakirKhalil [2] has pointed out.

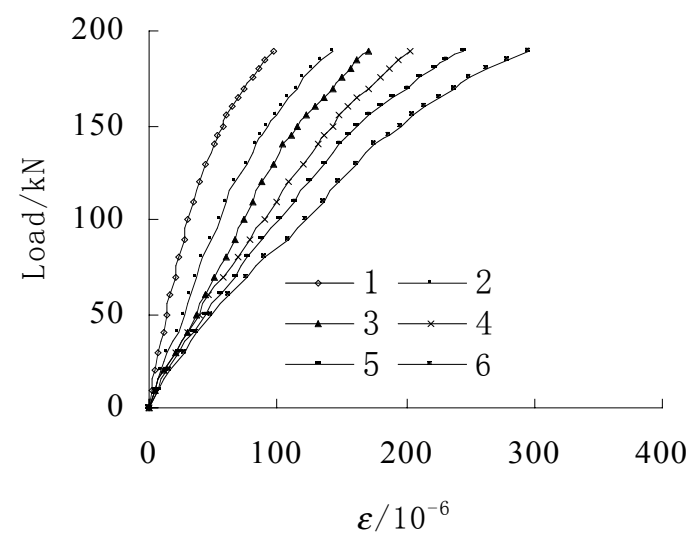

[6] Y. J. Liu, J. P. Liu, J. J. Chi, "Shear bond behaviors at interface of concrete-filled steel tube", Journal of Guangxi University, vol. 35, pp.17-23, Jan 2010.

[7] Y. J. Huang, J. Y. Xue, H. T. Zhao, J. B. Chu, "Experimental study of bond strength of concrete-filled square steel tube", Journal of Architecture and Civil Engineering, vol. 27, pp. 44-47, Jan 2010.

[8] C. Q. Rocker, B. Cameron, C. B. Brown, "Composite action in concrete filled tubes", Journal of Structual Engineering, vol. 125, pp. 477-484, May 1999.

[9] X. Chang, C. K. Huang, D. C. Jiang, Y. C. Song, "Push-out test of pre-stressing concrete filled circular steel tube columns by means of expansive cement", Construction and Building Materials, vol. 23, pp. 491-497, 2009.

[10] Y. M. Wei, Y. G. Zhou, B. Tomita, "Hydration behavior of wood cement-based composite I: evaluation of wood specimens

Fig. (11). Load-strain relationships for specimen e. 
effects on compatibility and strength with ordinary Portland cement", Journal of Wood Science, vol. 46, pp. 296-302, April 2000 .
[11] X. Lei, H. Chengkui, L. Yi, "Expansive performance of selfstressing and self-compacting concrete confined with steel tube", Journal of Wuhan University of Technology, vol. 22, pp. 341-345, Feb 2007.

(C) Kai-Cheng et al.; Licensee Bentham Open.

This is an open access article licensed under the terms of the Creative Commons Attribution Non-Commercial License

(http://creativecommons.org/licenses/_by-nc/3.0/) which permits unrestricted, non-commercial use, distribution and reproduction in any medium, provided the work is properly cited. 